\title{
Research on the Application and Promotion Strategy of the Support mode in the Ideological and Political Education of College Students under Constructivism

\author{
YANG Lei ${ }^{1}$
}

${ }^{1}$ Shaanxi institute of international trade \& commerce

Keywords: Constructivism; Scaffolding instruction; Ideological and Political Teaching; Application.

\begin{abstract}
Constructivism is the theoretical source of support mode, and the application of scaffolding teaching mode is helpful to improve the traditional teaching relationship, and provide the necessary conceptual framework for knowledge construction. College Students' Ideological and political teaching in scaffold model application should follow the principle of difference, diversity, applicability of, and through self inquiry teaching, with political news and other ways to stimulate students' potential, in order to improve college students' Ideological and political education level.
\end{abstract}

\section{建构主义下支架式模式 \\ 在大学生思政教学中的应用建设及推广策略研究}

\author{
杨蕾1 \\ 1陕西国际商贸学院，思政教研部
}

关键词:建构主义; 支架式教学; 思政教学; 应用

摘要.建构主义是支架式模式的理论源泉, 支架式教学模式的应用有助于改善传统的教学关 系, 为知识建构提供必要的概念框架。现阶段大学生对思政教学存在认知误区, 思政教学缺 乏针对性与全面性, 迫切要求引入支架式教学模式。大学生思政教学中支架式模式的应用应 坚持差异性、多元化、适用性的原则, 并通过自主探究式教学、结合时政新闻等方式激发学 生潜能，以提升大学生思政教学水平

\section{一、建构主义下支架式教学模式概述}

\section{1.建构主义理论的概念}

建构主义是由皮亚杰首先提出的，他指出人在与环境相互作用中，会逐渐建立起对外部 世界的认知体系, 并以此完善自身的知识结构。科尔伯格在研究认知体系发展条件的基础上, 进一步阐述了如何提高人的主动性 ${ }^{[1]}$ 。建构主义教学论指出, 学生是具有学习主动性的建构 者, 也是信息获取与加工的主体, 而非被动的信息接受者。在教学过程中应该着力激发学生 的主动性, 采用必要的手段引导学生主动建构知识体系。建构主义以学生为中心, 主张通过 合理引导培养学生主动探索、主动学习的意识, 帮助他们尽快建构所学知识的结构体系, 充 分发挥学生学习的主动性。该理论完全颠覆了传统的 “满堂灌” 教学理念, 成为国内外高校 教学改革的指导思想之一。

\section{2.建构主义下支架式教学模式}

建构主义可以看作支架式模式的指导性理论，而 “最近发展区” 理论的产生与传播，直 
接催生了支架式模式。维果茨基认为智力活动中人需要面对两个问题, 一方面是如何提高自 身能力, 另一方面是学习过程中存在的问题。这两方面问题之间存在较大差异, 教学的主要 目标就是消除或减小差异, 也可以将这一差异称作 “最近发展区”。这就是说教学过程中教 师不应该将注意力放在提升学生能力上, 而应该通过不断引导促进学生成长, 将学生引领至 更高的层次。在这一教学过程中 “支架” 发挥着重要作用, 可以看作构建 “最近发展区” 的 框架, 也发挥着教学引领作用。支架式教学可以看作全新的建构主义教学模式, 为学习者的 知识建构提供了概念框架, 改变了传统课堂教学中教师为主体的师生关系, 让学生积极参与 到课堂教学互动中, 进而引领学生自主学习更多知识。

\section{3.支架式教学模式的基本特征}

支架式教学模式认为教学过程中学生具有一定的基础认知能力, 而这些认知是他们学习 新知识、形成新理念的前提。教学中应做到 “以学生为中心”, 掌握每个学生的基础认知, 并定期检验他们在已有认知上获得的新认识, 以达到预期的教学效果。同时支架式教学模式 更加重视教学过程中师生之间的互动, 认为只有在互动情境中, 学生才能产生理解与探索的 动力, 也才能获得真正意义上的知识积累。此外, 支架式教学模式强调对 “最近发展区” 的 关注, 教师只有始终保持教学活动在最近发展区内, 才能强化学生已有的心理机能, 并且激 励学生形成全新的心理机能。

\section{二、现阶段我国大学生思政教学的现状与问题分析}

\section{1.思政教学存在认知误区}

由于高校思政教育本身存在一定的复杂性，加上大学生学业繁重，多将学习精力放在专 业课程上, 导致学生没有时间或不愿意认真理解与学习, 并且高校思想政治教育传统的教学 方式过于看重教学目标, 学生学习的主要目的就是应付考试, 对于思政知识的认知过于简单, 缺少动手、动脑与实践机会。这不仅不适应学生的自身发展需求, 也违背了思政教育的初衷。

\section{2.思政教学方法缺乏针对性}

大学思政课传统的教学模式, 是以教师课堂传授知识为主。这种模式忽视了学生学习过 程中的认知能力, 导致学生全程属于被动状态。这样不仅学生的积极性无法提高, 也难以得 到锻炼思维的机会, 很容易让学生失去学习兴趣。同时整个教学过程若教学形式单一, 或拘 泥于课本, 学生与教师之间缺乏必要的互动, 不仅无法活跃课堂气氛, 也难以提升教学效果。

\section{3.问题解答缺乏客观性与全面性}

大学生思政教学涉及到经济、政治、文化等多方面的内容 ${ }^{[2]}$ 。这些问题与大学生的现实生 活存在一定距离。而教材对部分问题缺乏系统与深刻的阐述，导致学生没有机会去理解并思 考这些问题，例如，高校思政教材《中国近现代史纲要》中提出坚持具有中国特色的政治制 度, 但是对其原因并没有详细论述。这很容易让学生产生困惑, 也增加了学习的难度。

\section{三、建构主义下支架式教学模式在大学生思政教学中的应用建设}

\section{1.支架式教学模式应用于思政教学的必要性}

随着近年来高校对学生主体地位的重视, 支架式教学模式顺利进入教学领域, 也为解决 传统教学模式存在的弊端提供了途径。将支架式教学模式应用于高校思政教学中, 完全符合 素质教育的要求，也符合对学生思想品质锤炼的要求。大学生思政教育中支架式教学强调将 学生作为主体, 通过设置合理的支架, 并创设与教学内容相关的情境, 提升学生课堂学习的 主动性, 提高他们原有的学习能力与知识水平。支架式教学模式也可以改善原有的教学环境, 创新思想政治教学方法, 提高思政教育的针对性, 帮助教师提升教学水平。 


\section{2.支架式教学模式应用于思政教学的基本原则}

结合已有研究成果与支架式教学经验总结，大学生思政教育中支架式教学模式的应用需 遵循以下原则：（1）多元化原则。针对不同的教学内容以及不同的教学情境, 应该制定不同 形式的教学支架。并且支架的提供者不仅有教师，也可以包括学生家长、社会人士等。 差异性原则。支架式教学模式强调掌握 “最近发展区”, 由于每个学生学习情况存在差异, 并且他们对思政内容与难题的认知千差万别, 思政教学中应坚持差异性原则。对于学习能力 强的学生, 在教学中可以减少支架数量, 或者设计部分比较抽象的支架, 也可以提前撤出支 架, 让他们尽快开展自主学习。对于学习情况相对较差的学生, 可根据需要尽量多设置相关 支架。（3）适时性原则。思政教学中支架的设计应该注重把握时机, 并且密切关注学生的学 习水平，根据每个学生的已有情况进行支架调整，以达到最佳教学效果。

\section{3.支架式教学模式应用于思政教学的关键点}

支架式教学模式就是在大学生思政教学过程中, 通过设置支架辅助学生完成各项学习目 标, 加深对思政知识与重难点的理解, 以获得最佳的教学效果。支架式教学的开展应该注意 “支架” 的合理搭建, 所谓支架就是教师根据 “最近发展区” 教学需求设置的相关教学问题 与任务, 可以帮助形成概念框架以为教学服务。大学生思政教学中支架的构建, 就是帮助学 生分步骤完成学习任务, 完成从已有知识向新知识的过渡 ${ }^{[3]}$ 。因此, 支架可以看作思政教学的 基本框架, 合理的支架搭建有助于提升教学效果, 反之则将增加教学难度。同时支架式教学 中要求明确 “最近发展区”，即教师应该掌握每个学生的实际学习情况，通过对不同教学任 务的合理分解, 帮助学生尽快掌握所学的内容, 引导学生进入更高的层次。在教学阶段也需 要根据需要不断调整支架, 并营造适宜的教学环境, 让学生学习全程均处于最近发展区, 或 接近最近发展区, 以保障思政教学课程的有效性。此外, 思政教学中支架的设计应注重循序 渐进, 不能一开始就增加支架的难度, 应该在保证学生理解的基础上, 逐渐增加支架的难度, 引导学生顺利进入新的学习情境中。在大学生思政教学中也可以将教学内容拆分为多个部分, 设置多样化的教学支架以提高教学效果。

\section{四、建构主义下支架式教学模式在大学生思政教学中的实践推广策略}

\section{1.实施自主探究式教学方法}

大学生思政教学中教师可以设置多样化的问题构建支架, 然后引导学生通过自主探究解 决问题, 以尽快突破最近发展区, 突破已有学习能力的瓶颈。自主探究式教学法基本分为三 步, 即提出问题、启发思维、自主探究。首先, 作为贯穿教学全过程的纽带, 问题设计应该 给学生留有思考与想象的空间, 尽量设计环环相扣的问题, 凸显思政教学循序渐进的特点。 其次, 应通过构建支架形成层层递进的思政教学路径, 引导学生主动启发思维。最后, 在自 主探究式教学中, 教师不仅应该思考如何构建支架, 也应该考虑如何引导并参与互动, 通过 与学生的密切联系激发学生潜能。一方面教师在讲解重点内容时, 可以根据热点事件进行合 理设问, 在学生全面了解事件过程的基础上, 要求他们对此事发表自己的观点, 然后提出更 加深刻的问题激发学生的探索欲望。另一方面教师也需要充分利用各种多媒体设备, 在教学 中向学生展示多样的教学案例, 让学生在全方位了解社会现象、政治问题的基础上, 灵活运 用所学知识提升思维能力, 不被传统思想所束缚。例如, 针对香港 “占中” 问题, 可以通过 设置 “占中的本质是什么？” “占中的政治背景如何？”等问题，引导学生在了解事件的基 础上认清本质, 分析香港社会非理性的一面, 分析西方势力对中国事务的暗中操作, 以及妄 图阻挠中国社会发展的意图。

\section{2.结合时政新闻增强学生兴趣}

信息时代大学生对新鲜事物具有极强的好奇心，也能够随时随地获取最新资讯 ${ }^{[4]}$ 。大学生 思政教学中可以将时政要闻作为学习内容, 结合多媒体将抽象的理论转化为新鲜的时事与热 
点, 提高学生课堂讨论的热情, 满足大学生的好奇心理。在支架式教学过程中, 教师搭建的 支架发挥着重要作用, 教师可以根据学生需求与教学内容, 设置不同的学习 “支架” , 让学 生借助 “支架” 增强兴趣, 最终达成教学目标。教师首先应该在学期初根据教学内容设置本 学期的重大理论问题, 让学生对学习内容有大致了解。其次, 向学生简要介绍本学期的重难 点与学习任务, 然后围绕国际国内时事要闻进行简要评价。第三, 在每堂课后要求学生进行 归纳总结, 引导他们将所学的知识与相关事件结合起来理智分析与探索, 并且适时点评以启 发学生思维, 拓展他们的思维空间, 进而提升思政教学的有效性。此外, 每个学生都可以根 据自己的理解发表观点, 并在课堂上分组开展探讨交流活动, 引导学生将情感理论与社会现 象结合起来, 通过对问题的再认识检验所学知识, 师生之间也可以借助微信等开展课后在线 交流，以加深对思政理论知识的理解。

\section{3.优化大学生思政教学评价机制}

支架式教学模式强调学生的主体性, 大学生思政教学中学生应该积极参与到教学活动中, 而教师应该通过合理引导分析, 观察每个学生的课堂表现, 并且根据学生表现进行合理评价。 可以将教学评价分为不同的等级, 并将其纳入学生成绩档案中, 以激发学生的学习动力, 增 进师生之间的教学互动。同时, 应引入道德评价机制, 保障教学内容与新课程教学要求相契 合, 全面提升学生的综合素质。最后, 应改变传统的单一式评价标准, 体现思政教学评价形 式的多样性。教师可以采用闭卷考试、开卷考试、撰写调研报告、时事要闻分析等多种方式, 培养学生思维逻辑、实践探索等多方面的能力。通过书面考试可以检验学生的理论知识学习 情况, 提高学生的记忆能力与理解能力, 帮助学生形成完善的知识结构。而撰写文章可以提 高学生的问题分析能力, 引导学生利用课本知识深入分析社会现实问题, 增强学生解决实际 问题的能力。

\section{五、结语}

建构主义下支架式教学属于开放、交互的全新教学方式, 有助于思政教学中师生之间的 多向多维互动。借助支架式教学不仅可以改变传统思政教学中单一的教学形式与评价机制, 增进师生之间的关系, 也可以通过合理的课堂支架设计感染学生, 在自由、沟通、平等的教 学氛围中达成情感共鸣。当前大学生思政教学中应合理引入并推广支架式教学法, 通过正确 引导提升学生的学习自觉性, 从而全面提升他们的综合素养。

\section{References}

[1] LEI Xiao and ZHU Xue-ling and CHEN Lin, Subliminal Message : A New Way of Improving the Effect of Ideological and Political Education, National Defense Science \& Technology, pp. 30-33, vol.34, 2013.

[2] RAN Hui-zhen, Scaffolding instruction model application in teaching deng xiaoping theory, Education Teaching Forum, pp. 181-182, Feb.2015.

[3] Scaffolding instruction in the application of multimedia technology foundation course, Informatization Construction, pp. 285-286, Oct.2015. 